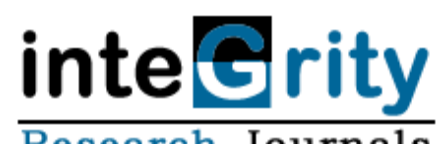

Journal of Agricultural Science and Practice

Volume 4(2), pages 43-49, April 2019

Article Number: F74248683

https://doi.org/10.31248/JASP2019.128

ISSN: 2536-7072

http://integrityresjournals.org/journal/JASP

Full Length Research

\title{
Determinants of vulnerability of headed households to food insecurity in Lafia Local Government Area, Nasarawa State, Nigeria: A gender based analysis
}

\author{
Onuk, E. G. ${ }^{*}$, Girei, A. A. and Luka, E. G. \\ Department of Agricultural Economics and Extension, Faculty of Agriculture, Nasarawa State University, Keffi, Nigeria. \\ *Corresponding author. Email: galadima1954@gmail.com
}

Copyright @ 2019 Onuk et al. This article remains permanently open access under the terms of the Creative Commons Attribution License 4.0, which permits unrestricted use, distribution, and reproduction in any medium, provided the original work is properly cited.

Received 19th February, 2019; Accepted 18th March, 2019

\begin{abstract}
This study examined the determinants of vulnerability of headed households to food insecurity in Lafia Local Government Area, Nasarawa State, Nigeria: A gender based analysis. The specific objectives were to describe the socioeconomic characteristics of male and female headed households in the study area; identify the determinants of vulnerability of households to food insecurity and identify the effects of food insecurity on male and female headed households in Lafia Local Government Area. A two-stage sampling technique was adopted to select the respondents. The data were analyzed using simple descriptive statistics such as mean, frequency counts and percentages, t-test and linear regression. Majority of male and female headed households had secondary education and low income level. The result also indicated that there was significance difference in the effects between male and female headed households in the study area, implying that the female headed households are more vulnerable to the determinants of food insecurity compare to the male headed households. The result also revealed that the effect of the independent variables which are the determinants of vulnerability of headed households to food insecurity indicated that three variables, farm size, educational level and income level had a positive relationship, while sex (gender), marital status, occupation, type of labour and access to extension had a negative relationship. The $\mathrm{R}^{2}=0.196$ implies that about $20 \%$ of the analysis predicted that the independent variables were selected on the level of headed household's food insecurity effect on vulnerability to food insecurity. The result therefore recommended for further studies to be conducted on the area of food security by considering detail and accurate information on various variables including political, climatic and weather (rainfall and temperature), topography, natural disasters, ecological conditions and other factors that affect food security.
\end{abstract}

Keywords: Dietary needs, food insecurity, food security, headed households, urban poor, vulnerability.

\section{INTRODUCTION}

Food insecurity is a situation that exists when all people, at all times, do not have physical, social and economic access to sufficient, safe and nutritious food that meet their dietary needs and food preferences for an active and healthy life (Okezie et al., 2011), while on the other hand, "Food security exists when all people at all times have physical and economic access to sufficient, safe and nutritious food that meet their dietary needs and food preferences for an active and healthy life" (Okezie et al.,
2011). This widely accepted definition also reinforces the multidimensional nature of food security which includes: food access, food availability, food utilization and stability among others (WHO, 2013).

In recent years, there has been increasing awareness that the analysis of food insecurity should be carried out in a dynamic context. It is essential not just to look at the current incidence of an inadequate nutritional outcome, but also to identify the individuals, households or the commu- 
nities who are more at risk of suffering in the future. The main analytical concept that has been developed in order to address the issue of the future incidence of food insecurity is vulnerability analysis. The notion of vulnerability had first been applied to the context of poverty, for an early application to social risk management, but it is increasingly acknowledged as an important approach for the analysis of food insecurity as well (Ibrahim et al., 2016). Food insecurity, they said, is the "unavailability at all times of adequate world food supplies of basic foodstuffs to sustain a steady expansion of food consumption and to offset fluctuations in production and prices" (Admassie et al., 2017). Onoja (2017) indicated that policies aimed at reducing household population growth could improve household welfare by increasing economic growth and improved nutrition for the growing workforce and equally reduce food insecurity.

Food availability is achieved when sufficient quantities of food are consistently available to all individuals within a country. Such food can be supplied through household production, other domestic output, commercial imports or food assistance. For persons living in urban areas, food access hinges primarily on the household's ability to purchase food. Most urban poor neither have large food stores, nor do they have access to areas for own food production. The urban poor often pay more for food purchases than do wealthier urban counterparts, as they are obliged to buy small quantities of food daily because they do not have the resources or living conditions which permit them to purchase and store large quantities of food at home (IFPRI,2017; Costello, 2017).

Effective food utilization depends in large measure on knowledge within the household of food storage and processing techniques, basic principles of nutrition and proper child care. The primary factor effecting food utilization is individual health status. Illness and disease can lead to loss of appetite and poor absorption of the nutrients ingested. Environmental contamination is a large factor contributing to poor food utilization. The safety of food in the urban environment is a subject of concern. Street foods are often prepared under unhygienic conditions, and can contribute to outbreaks of food- borne illness. The health status of any group will be influenced by access to services, including primary health care and education, as well as potable water, sanitation systems and general environmental conditions (Costello, 2017).

Availability, access and utilization are hierarchical in nature (IFPRI, 2017; Costello, 2017). Food availability is necessary but not sufficient for food accessibility and access is necessary but not sufficient for utilization. In a larger sense, two broad groups of factors determine food security. These are supply side factors and demand side factors. The supply-side factors are those that determine food supply or food availability. In other words, they are determinants of physical access to food at national, household and intra-household levels (IFPRI, 2017; FAO,
2017).

The demand side factors on the other hand are factors that determine the degree of access of countries, households and individuals to available food. They are, in other words, determinants of economic access to food or determinants of entitlement to available food. The minimum is related to, among other things, body size, weight, sex, nature of work and, for women, pregnancy or lactation status. Food security at the sub-national level means the assured availability of food for individual households to draw on to meet their minimum consumption requirements during a given period (Costello, 2017).

Food security is the ability of poor countries, poor families and poor individuals to purchase sufficient quantities of food from existing supplies. Improving food security requires both increasing the purchasing power of the poor and boosting overall food production. Developing countries can develop a two-pronged strategy to promote food security. In the long run, efforts must be made to increase the purchasing power of the poor by raising the overall level of food production in the third world (UNDP, 2016). Increased food supplies and purchasing power must be inextricably linked to elements of any long-term food security efforts. In the short run, redistributing food supplies from the developed to the developing world is likely to be the best way to meet the more immediate food security needs of the poor (World Bank, 2017).

There is other concept of food security that is worth mentioning here; that is the issue of food insecurity. It is believed that people who frequently do not have enough to eat according to accepted cultural norms created a crisis. For this reason, the phrase 'Food Insecurity' was used to describe the instability of or regional food supplies over time. It was then expanded to include lack of secure provisions at the household and individual level. Food insecurity concern is due to inadequate physical availability of food supplies, poor access among the population, or inadequate utilization of food (Onoja, 2017).

According to United Nations Development Programme (UNDP, 2016), the concept of food insecurity has evolved, developed, multiplied and diversified since the world food conference of 1974 . The main focus has shifted from global and national to household and individual food insecurity and from food availability to food accessibility and the security of access.

The continued increase in globalization and integration of food market has intensified competition and efficacy in Agriculture. Yet in the same vain, agriculture faces a range of modern and serious challenges, particularly in developing countries that are exposed to price shocks and climate change and continued deficiencies in infrastructure in rural areas in addition to growing population, growing demand for food, rising poverty, economic stagnation, climate change and worsening environmental degradation. Food insecurity has caused a lot of challenges which are 
very huge and thereby reducing efficiency and maximization in small holder farm productivity. To empower male and female house hold head with knowledge on determinants of vulnerability of food insecurity and its effect and increase their productivity and income as well as protect their food security and livelihoods and to harness knowledge effectiveness to complex rapidly changing global market (avoiding falling behind the technology curve). Onuk (2016) reported that one way of increasing farm output is the cropping systems where crops continue to be grown in traditional formats with limited scientifically established cultural practices that would exploit interaction between two or more crops for maximum yield and weed suppression. Food insecurity reduces diversity of diet and income, causes instability of production, and increases insect pest and disease incidence, inefficient use of labour, and drastic or gradual reduction of food production with limited resources and also minimization of returns under low levels of technology. This study is justified given that most researches on food insecurity always focused on the aspects of effect and less emphasis on determinants of vulnerability to food insecurity issues for sustainable agricultural development. The results from this will be useful for policy makers to come up with policies that will address the problems faced by farmers' production, thus increasing local production. The study will also demonstrate on the extent of profitability of farming system to reduce food insecurity and thus encourage people to embark on ways to control determinants of vulnerability that lead to food insecurity. Intending researchers will find the work as a useful guide in their efforts to carry out similar research elsewhere.

\section{Objective of the study}

1. Describe the socio-economic characteristics of the male and female households in the study area.

2. Identify the effects of food insecurity on male and female headed households.

3. Identify the determinants of vulnerability of households to the food insecurity.

\section{METHODOLOGY}

\section{Study area}

The study was conducted in Lafia local government area of Nasarawa state, Nigeria. The local government is located between $8^{0}$ and $9^{\circ}$ East of the Greenwich meridian and latitude $8^{0}$ and $9^{0}$ north of the equator. In terms of the vegetation, the local government lies largely within the guinea savannah ecological zone. Its wet season starts from March/May to October. The local government area has an annual average rainfall of about $1,288 \mathrm{~mm}$ and an average temperature of about $32^{\circ} \mathrm{C}$. Sandy, loamy and clay fine sand and silt are found in Fadama areas. The major occupation of the people in the area include farming of upland crops such as millet, sorghum, groundnut, cowpea, etc. and in the dry season major crops include vegetable crops like tomatoes, hot pepper, garden egg, (Adefila, 2014; Abaje et al., 2015). According to the National Population Commission (2006), the local government has a total population of 478,809 people consisting mainly of Kanuri, Hausa, Fulani, Alago, Koro, Eggon, Gwanilanekye, Rindre, etc. (Lafia Local Government Information Unit, 2008). The local government is made up of 13 districts among which are Lafia north, Lafia south, Lafia east, Lafia west, Lafia centre, Agyaragu, Akunza, Assakio, Shabu and Kwandare, etc. The local government shares boundaries with the following Local government areas; Nasarawa-Eggon in the north, Doma in the west, Obi in the south and finally Qua'an Pan local government area in plateau state in the east.

\section{Sampling technique}

A purposive sampling technique was used for this study. A two-stage sampling technique were adopted to select the respondents. The first stage was the random selection of three (3) districts from Lafia Local Government Area and the selection of four (4) villages which include (Danka, Akurba, Akunza, Kwandare). The second stage was the selection of twenty (20) respondents (10 male and 10 female respectively) per village making a total of eighty (80) respondents for the study.

\section{Data collection and analysis}

Primary data were used for this study. The data were collected with the aid of a structured questionnaire which were administered to the respondents. Data were collected on the socio-economic characteristics of the respondents in the study. Descriptive analysis such as mean, frequency and percentage were used to achieve objectives 1; t-test and simple regression analysis were used to achieve objectives 2 and 3, respectively. The estimated simple regression model was specified as follows:

$Y i=\beta_{0}+\beta_{1 \times 1}+\beta_{2 \times 2}+\beta_{3 \times 3}+\beta_{4 \times 4+} \beta_{5 \times 5}+\beta_{6 \times 6}+\beta_{7 \times 7}+\beta_{8 \times 8+U i}$

Where: $Y i=$ Level of household insecurity, $X_{1}=$ Sex (gender) male $=1$, female $=0, \quad X_{2}=$ Marital Status (Married $=1$, single $=0$ ), $X_{3}=$ Occupation, $X_{4}=$ Education level, $X_{5}=$ Type of Labour, $X_{6}=$ Income Level, $X_{7}=$ Farm size of farmers (in hectares), $X_{8}=$ Access to extension services, $\beta=$ Constant and $\mathrm{Ui}=$ Error term. 


\section{RESULTS AND DISCUSSION}

\section{Socio-economic characteristics of the respondents}

The socio-economic characteristics of the respondents are presented in Table 1. The Table 1 shows that the age of most male headed household respondents' range between $20-25$ (17.5\%), 26-30 (10.5\%), 31-35 (22.5\%), $36-40(40.3 \%)$ and 40 and above (10.0\%). This result shows that majority of male headed respondents were at the age range of $36-40(40.3 \%)$. The female headed household respondents' range between 20-25 (25.0\%), $26-30(22.5 \%), 31-35(30.0 \%), 36-40(12.3 \%)$ and 40 and above (10.0\%). This shows that the females' age range of 31-35 had the highest percentage (30.0\%). This implies that the male and female headed households were in their middle or youthful age in the study area. The result indicated that the respondents are in their active work life and can struggle to get food.

The result further revealed that male (40) and female (40) were purposively sampled in order to examine the coping strategies employed and identify the determinants of vulnerability to food insecurity. The selection was based on equal basis to avoid bias in the research. The result revealed that greater proportion of the male headed household respondents $20(57.5 \%)$ were married, while 8 $(20.0 \%)$ were single, the female headed household indicated that $27(67.5 \%)$ were married, while 6(15.0\%) were single. This implies that majority of the male and female headed household were married. Furthermore, the family size of the male headed household respondents was $42.5 \%$, while the female headed household had $47.5 \% \mathrm{~h}$ This indicates that the male and female headed households had large family size and this has implication on food security because, the larger the family size the more food is consumed.

The education level of the respondents revealed that majority $12(32.5 \%)$ of male headed households had secondary education while the $16(40.0 \%)$ of the female headed household had secondary education. This implies that the female headed household are slightly more educated than the male headed household. The Table 1 revealed that the male headed households had $20.0 \%$ high income level, $42.5 \%$ had low income level and $37.5 \%$ moderate income level, while the female headed households had $40.0 \%$ moderate and $60 \%$ low income. This implies that the male headed household earn more income than the female headed household because they engage more in business activities compare to the female headed household. This is in line with Shiferaw et al. (2003), who reported that business activities such as trading and farming is a factor that constitute the increase of male farmers' income.

The result from the Table 1 also indicated that majority $25(62.5 \%)$ of the male headed households and majority $24(60.7 \%)$ of the female headed households used family members as source of labour. Table 1 further revealed that majority $(67.5 \%)$ of the male headed households do not have access to extension services and majority (55.0\%) of the female headed households do not have access to extension services. This implies that both the male and the female headed households had no access to extension services. The result from the Table 1 further revealed that the majority $(67.5 \%)$ of the male headed households had farm size of $>1$ to 2 hectares. and the majority (90.0\%) of the female headed households had farm size $<1$ to 2 hectares. This implies that majority of the male headed household had more farm size for farming activities than female headed household and this is in agreement with the work of Mucavele (2001), who reported in his work in Ethopia that male have access to more land for farming activities than female farmers.

The result of the t-test in Table 2 presents the effect of determinants of food insecurity to male and female headed households in Lafia Local Government Area, Nasarawa State, Nigeria. The mean effect of determinants of food insecurity to the male headed household was 4.8750 and that of the female headed household was 5.0750; this implies that the mean difference was 0.20000 . The calculated t-value was 0.399 which is less than the table value of 1.962 at $3 \%$ level of significance. Therefore, this suggests that there is significance difference in the effects of determinants of food insecurity between male and female headed households in the study area. The result revealed that the female headed household are more vulnerable to the determinants of food insecurity through the effect as compared to the male headed households.

Table 3 shows the regression estimation of determinants of vulnerability to food insecurity among male and female headed households. The result revealed that the combine effect of independent variables (marital status and educational level were significant at $5 \%$ while farm size was significant at $10 \%$ ) on the level of household food insecurity $(Y)$. However, sex, income level, occupation, type of labour and access to extension were not significant. The effect of the independent variables which are the determinants of vulnerability of headed households to food insecurity indicated that three variables which are farm size, educational level and income level had a positive relationship, this implies that the higher the farm size, the higher educational level and the higher the income level, the less vulnerability or decrease in food insecurity among men and women headed households in the study area. While the result revealed that sex (gender), marital status, occupation, type of labour and access to extension had a negative relationship and impact respectively on the determinants of vulnerability to food insecurity, this implies that decrease in the number of male and female headed households will result to the increase in food insecurity. However, marital status, type of occupation, type of labour and lack of access to extension services have negative impact which will result to households more vulnerable to 
Table 1. Socio-economic characteristics of the respondents.

\begin{tabular}{|c|c|c|c|c|}
\hline \multirow{2}{*}{ Parameters } & \multicolumn{2}{|c|}{ Male headed household } & \multicolumn{2}{|c|}{ Female headed household } \\
\hline & Frequency & Percentage (\%) & Frequency & Percentage (\%) \\
\hline Sex & 40 & 50 & 40 & 50 \\
\hline \multicolumn{5}{|l|}{ Age (Years) } \\
\hline $20-25$ & 7 & 17.5 & 10 & 25.0 \\
\hline $26-30$ & 4 & 10.0 & 9 & 22.5 \\
\hline $31-35$ & 9 & 22.5 & 12 & 30.0 \\
\hline $36-40$ & 16 & 40.0 & 5 & 12.5 \\
\hline 40 Above & 4 & 10.0 & 4 & 10.0 \\
\hline Total & 40 & 100.0 & 40 & 100.0 \\
\hline \multicolumn{5}{|l|}{ Marital status } \\
\hline Single & 8 & 20.0 & 6 & 15.0 \\
\hline Married & 23 & 57.5 & 27 & 67.5 \\
\hline Divorce & 5 & 12.5 & 4 & 10.0 \\
\hline Widowed & 4 & 10.0 & 3 & 7.5 \\
\hline Total & 40 & 100.0 & 40 & 100.0 \\
\hline \multicolumn{5}{|l|}{ Family size } \\
\hline $1-5$ & 17 & 42.5 & 19 & 47.5 \\
\hline $6-10$ & 9 & 22.5 & 14 & 35.0 \\
\hline $11-15$ & 8 & 20.0 & 4 & 10.0 \\
\hline 16 and above & 6 & 15.0 & 3 & 7.5 \\
\hline Total & 40 & 100.0 & 40 & 100.0 \\
\hline \multicolumn{5}{|l|}{ Educational level } \\
\hline Primary & 7 & 17.5 & 9 & 22.5 \\
\hline Secondary & 13 & 32.5 & 16 & 40.0 \\
\hline Tertiary & 5 & 12.5 & 5 & 12.5 \\
\hline Adult education & 10 & 25.0 & 7 & 17.5 \\
\hline Non formal education & 5 & 12.5 & 3 & 7.5 \\
\hline Total & 40 & 100.0 & 40 & 100.0 \\
\hline \multicolumn{5}{|l|}{ Income level } \\
\hline High & 8 & 20.0 & & \\
\hline Moderate & 15 & 37.5 & 16 & 40.0 \\
\hline Low & 17 & 42.5 & 24 & 60.0 \\
\hline Total & 40 & 100.0 & 40 & 100.0 \\
\hline \multicolumn{5}{|l|}{ Occupation } \\
\hline Trader & 10 & 25.0 & 13 & 32.5 \\
\hline Farmer & 30 & 75.0 & 27 & 67.5 \\
\hline Total & 40 & 100.0 & 40 & 100.0 \\
\hline \multicolumn{5}{|l|}{ Type of labour } \\
\hline Family & 25 & 62.5 & 24 & 60.0 \\
\hline Communal labour & 9 & 22.5 & 7 & 17.5 \\
\hline Hired & 5 & 12.5 & 7 & 17.5 \\
\hline Others & 1 & 2.5 & 2 & 5.0 \\
\hline Total & 40 & 100.0 & 40 & 100.0 \\
\hline
\end{tabular}


Table 1. Contd.

\begin{tabular}{|c|c|c|c|c|}
\hline \multicolumn{5}{|c|}{ Access to extension agent } \\
\hline No & 27 & 67.5 & 22 & 55.0 \\
\hline Yes & 13 & 32.5 & 18 & 45.0 \\
\hline Total & 40 & 100.0 & 40 & 100.0 \\
\hline \multicolumn{5}{|c|}{ Farm size } \\
\hline$<1-2$ & 27 & 67.5 & 36 & 90.0 \\
\hline $3-4$ & 11 & 27.5 & 4 & 10.0 \\
\hline 5 Above & 2 & 5.0 & & \\
\hline Total & 40 & 100.0 & 40 & 100.0 \\
\hline
\end{tabular}

Source: Data analysis, 2018.

Table 2. Showing the comparing effect of determinant to vulnerability of male and female headed household.

\begin{tabular}{|c|c|c|c|c|c|c|}
\hline \multirow{2}{*}{ Determinant } & \multicolumn{2}{|c|}{$\begin{array}{l}\text { Male Headed Household } \\
\mathrm{N}=40\end{array}$} & \multicolumn{2}{|c|}{$\begin{array}{l}\text { Female Headed Household } \\
\mathrm{N}=40\end{array}$} & \multirow{2}{*}{$\begin{array}{c}\text { Mean } \\
\text { Difference }\end{array}$} & \multirow[t]{2}{*}{ T-Value } \\
\hline & Mean & SD & Mean & SD & & \\
\hline Effect & 4.8750 & 2.36630 & 5.0750 & 2.10479 & 0.20000 & $0.399^{*}$ \\
\hline
\end{tabular}

*significant at $10 \%$.

Table 3. Determinants of vulnerability of household to food insecurity.

\begin{tabular}{lccccc}
\hline Variables & $\begin{array}{c}\text { Unstandardized } \\
\text { Coefficients }(\boldsymbol{\beta})\end{array}$ & $\begin{array}{c}\text { Standardized } \\
\text { Coefficients }(\boldsymbol{\beta})\end{array}$ & $\begin{array}{c}\text { Standard } \\
\text { Error }\end{array}$ & t-value & Sig. \\
\hline (Constant) & 4.916 & - & 1.714 & 2.868 & 0.005 \\
SEX & -0.454 & -0.102 & 0.541 & -0.839 & $0.404^{\mathrm{NS}}$ \\
Marital Status & -0.764 & -0.273 & 0.342 & -2.237 & $0.028^{\star *}$ \\
Farm Size & 0.576 & 0.266 & 0.315 & 1.825 & $0.072^{*}$ \\
Educational Level & 0.444 & 0.258 & 0.218 & 2.041 & $0.045^{\star \star}$ \\
Income level & 0.258 & 0.078 & 0.416 & 0.620 & $0.537^{\mathrm{NS}}$ \\
Occupation & -0.206 & -0.042 & 0.589 & -0.349 & $0.728^{\mathrm{NS}}$ \\
Type of labour & -0.285 & -0.113 & 0.293 & -0.973 & $0.334^{\mathrm{NS}}$ \\
Access to extension & -0.203 & -0.058 & 0.409 & -0.496 & $0.622^{\mathrm{NS}}$ \\
\hline
\end{tabular}

**Significant at $5 \%$, *significant at 10\%, NS=Not Significant, $\mathrm{R}^{2}=.196$.

Source: Field survey, 2018.

food insecurity in the study area. The $\mathrm{R}^{2}=0.196$ implies that $20 \%$ of the analysis predicted that the independent variables selected on the level of household food insecurity have effect on vulnerability to food insecurity.

\section{Conclusion}

This research examines the determinants of food insecurity among male and female headed households in the study area. The result used descriptive statistics to measure the vulnerability to food insecurity base on respondents frequency and severity of level of households to food insecurity, and also to examine the determinants of vulnerability using t-test and regression analysis to compare the gender that is mostly affected to vulnerability to food insecurity more. The following conclusion emerges from the research: Firstly, there is greater inequality in terms of resource availability to male and female headed households in the study area. Male headed households possess more resources than female headed households for example annual household income is significantly higher in male than female headed households. This research like many other studies confirms the presence of 
gender differences in household resources availability and allocation in Nigeria. Specific polices providing increase access to education, land and off land activities for female headed households would be needed to remove the gender disparity.

Secondly, directly linked to the above, the female headed households are more vulnerable to food insecurity, using strategies in the result, the measures show that female headed households suffer more effect compare to the male headed households. This result calls for conscious effort to increase and equip female headed households with education and provision of resources, opportunity for employment and income to reduce poverty and stress.

Finally, the result revealed that marital status, farm size and educational level were significant in determining food vulnerability in the gender household. This implies that increase in marital status, farm size and educational level will reduce the risk of the gender base falling into food insecurity in the future in Lafia Local Government Area, Nasarawa State and Nigeria as a whole.

\section{CONFLICT OF INTEREST}

The authors declare that they have no conflict of interest.

\section{REFERENCES}

Abaje, I. B., Ogoh, A. O., Amos, B. B., \& Abashiya, M. (2015). Climate change, flood disaster assessment and human security in Katsina State, Nigeria. American Journal of Human Ecology, 4(4), 47-56.

Adefila J. O. (2014). Pattern of Agricultural Development in Southern Parts of Katsina State, Nigeria: Notion for Rational Planning. IOSR Journal of Agriculture and Veterinary Science, 7(1), 14-20.

Admassie, A., Nuru, S., \& Megquier, S. (2017). Harnessing the demographic dividend in Ethiopia. Population Reference Bureau. Retrieved on 16/08/2017 from http://www.prb.org/Publications/Articles/2017/Harnessing-theDemographic-Dividend-in-Ethiopia.aspx

Costello, M. K. (2017) Agricultural development. Retrieved on 11/08/2017 from https://advocacy.thp.org/2014/08/08/maputoto-malabo-african-unions-declarations-commits-nations-toinvest-in-agricultural-development/

Food and Agricultural Organization (FAO) (2017). Strengthening sector policies for better food security and nutrition results: Climate change. Policy Guidance Note 5. FAO: Rome.
Ibrahim, H. Y., Adeola, S. S., \& Ibrahim, H. I. (2016). Determinants of food insecurity among farming households in Katsina State, north western Nigeria: An ordinal logit regression approach. Journal of Agricultural Sciences, 61(3), 291-301.

International Food Policy Research Institute (IFPRI) (2017). 2017 Global Food Policy Report. Washington, DC: International Food Policy Research Institute. DOI: 10.2499/9780896295827

Lafia Local Government Information Unit (2008). Report obtained from Lafia Local Government Information Unit, Nasarawa State, Nigeria.

Mucavele, J. U. (2001). Development and Poverty in Ethiopia 1995/96-2010/11. Addis Ababa, Ethiopia.

National Population Commission (NPC) (2006). Lafia Local Government population reports obtained from National Population Commission of Nigeria.

Okezie, C. A., Aloysius, C. N., \& Amir, H. B. (2011). Rising food insecurity: dimensions in farm households. American Journal of Agricultural and Biological Science, 6(3), 403-409.

Onoja, A. O. (2017). The role of multi-stake holders in addressing food security and other critical challenges of agricultural development in Nigeria. A paper presented at the 4th Annual Agricultural Policy Research Networks (APRNet) 4th APRNet National Multi-Stakeholders Forum on "Making Agricultural Research Work for End-Users" on 23rd August, at Valencia Hotels, Wuse II, Abuja, Nigeria.

Onuk, E. G. (2016), Comparative study of efficiencies of cowpeamaize and groundnut-millet intercropping systems in North Central Zone, Nigeria. Unpublished PhD Thesis Submitted to the department of Agricultural Economics, Management and extension, Faculty of Agriculture and Natural Resources Management, Ebonyi State University, Abakaliki.

Shiferaw, F., Richard, L., \& Christy, G. (2003). Determinants of food security in Southern Ethiopia": Food and Resource Economics Department, Institute of Food and Agricultural Sciences, University of Florida Gainesville, Florida 326110240.

United Nations Development Programme (UNDP) (2016). About Nigeria. Retrieved on 1/09/2017 from http://www.ng.undp.org/content/nigeria/en/home/countryinfo/

World Bank (2017) The World Bank in Nigeria. Retrieved on $15 / 08 / 2017$ from

http://www.worldbank.org/en/country/nigeria/overview

World Health Organisation (2013). 